\title{
A CATEGORIA "POBREZA" NAS FORMULAÇÕES DE POLÍTICA SOCIAL DO BANCO MUNDIAL
}

\author{
Vivian Domínguez Ugá
}

\begin{abstract}
RESUMO
Tendo em vista um dos objetivos atuais do Banco Mundial - o da "luta contra a pobreza" -, este trabalho propõe-se a contextualizar o momento da incorporação da categoria "pobreza" no receituário dessa instituição, por meio da análise de alguns de seus relatórios que tratam do tema, para, em seguida, analisar qual o significado do uso desse conceito na formulação de propostas de políticas sociais para os países "em desenvolvimento". Sugere-se que o uso do conceito de pobreza refere-se a um marco teórico bem definidoproposto pelo neoliberalismo -, que, ao priorizar os "pobres" como alvo de suas políticas, implica o deslocamento da política social da noção universalizada de "direito” e, em última instância, sugere a supressão da idéia e da realidade da cidadania social.
\end{abstract}

PALAVRAS-CHAVE: pobreza; neoliberalismo; políticas sociais; Banco Mundial.

\section{INTRODUÇÃO}

É notória a centralidade que o conceito "pobreza" passou a assumir desde início dos anos 1990, sobretudo em função de sua ampla utilização, tanto em relatórios de organismos internacionais quanto em documentos de formulação e avaliação de políticas públicas, principalmente de países seguidores das recomendações dessas agências.

Diante de tal evidência, busca-se mostrar neste artigo que, a partir da análise das recomendações de combate à pobreza do Banco Mundial, é possível identificar uma "teoria" social implícita delineada em seus relatórios, que, por um lado, sugere um tipo específico de política social e, por outro, descreve e reafirma o modelo de sociedade característico da atual configuração da ordem social, ou seja, o mundo que sucedeu à crise do Welfare State e à derrocada do mundo comunista.

Nesse sentido, pretende-se explorar aqui que o que poderia ser visto como uma mudança de política - de uma política apenas voltada para o ajuste fiscal para uma política mais "social" (por meio do "combate à pobreza") - faça parte da própria lógica do marco teórico do neoliberalismo: políticas focalizadas e compensatórias voltadas para "pobres".

Para tanto, serão analisados os relatórios do Banco Mundial, sobretudo aqueles voltados para a temática da "pobreza". Posteriormente, sugerir- se-á que o uso do conceito de pobreza refere-se a um marco teórico definido - proposto pelo neoliberalismo -, que, ao priorizar os pobres como alvo de suas políticas, implica o deslocamento da política social da noção universalizada de direito e, em última instância, sugere a supressão da idéia e da realidade da cidadania social.

\section{ANTECEDENTES}

A partir dos anos 1970, a chamada "Era de Ouro" (HOBSBAWM, 1995, p. 253) característica do período posterior à II Guerra Mundial, entrava em crise. Assistia-se no mundo desenvolvido a um quadro de diminuição do crescimento, queda dos investimentos no setor produtivo e aceleração geral dos preços, endividamento dos governos - o que representou, em última instância, tanto a falência do modelo fordista de acumulação capitalista quanto a crise da ordem social do Welfare State.

No esforço de lidar com essa crise, o chamado "neoliberalismo" começou a ganhar terreno e emergiu como contraponto político, econômico e ideológico à predominância da intervenção estatal característica da Era de Ouro. Resgataram-se e disseminaram-se idéias que, desde 1947, vinham sendo discutidas, nas reuniões da Sociedade de Mont Pèlerin ${ }^{1}$, cujo propósito era combater a po-

\footnotetext{
${ }^{1}$ Seus principais expoentes eram Friedrich Hayek, Milton Friedman e outros (cf. ANDERSON, 1995).
} 
lítica econômica keynesiana e o padrão de proteção social do Welfare State e preparar as bases para um outro tipo de capitalismo para o futuro: o capitalismo liberal.

Em defesa do Estado mínimo, seu objetivo prático era desvalorizar as diversas formas de intervenção estatal na economia. Aos poucos, foram conseguindo conquistar o senso comum com esse tipo de retórica, que chegou à Europa no final dos anos 1970. Em 1979, na Inglaterra, assistiu-se à adaptação do discurso neoliberal à realidade política nacional com Margaret Thatcher; em 1980, nos Estados Unidos, com Ronald Reagan, e, a partir daí, um crescente processo de difusão do ideário neoliberal pelo mundo. Nos países avançados, as propostas neoliberais consistiram na redução do papel do Estado, no enfraquecimento dos sindicatos e na flexibilização do mercado de trabalho.

Já na América Latina, a difusão desse ideário deu-se de modo um pouco diferente. Em primeiro lugar, é importante levar em consideração o que significou a Era de Ouro para os países latinoamericanos. Enquanto nos países centrais ela representou o auge do Welfare State e do keynesianismo, na América Latina, a Era de Ouro foi marcada pelo desenvolvimentismo (WALLERSTEIN, 2000), que entrou em crise nos anos 1980 .

O processo de desenvolvimento econômico nesses países, nos anos 1950 e 1960, realizou-se via endividamento externo. Por exemplo, o desenvolvimento econômico brasileiro foi realizado, segundo Castro (CASTRO \& SOUZA, 1985), em marcha forçada, ou seja, o governo escolheu endividar-se naquele momento para, depois, resolver o que fazer com a dívida externa resultante dessa opção. A economia brasileira entrou em crise no fim dos anos 1970, com o segundo choque do petróleo - em 1979 -, momento em que sofreu drasticamente: por exemplo, houve um aumento da dívida externa em função do aumento das taxas de juros internacionais e uma drástica redução da entrada de recursos externos no país (decorrente da perda de confiança na administração da economia brasileira, sobretudo após a moratória mexicana, em 1982).

Foi nesse contexto, então, que as idéias neoliberais chegaram e foram aplicadas na América Latina. Primeiramente, houve a experiência da ditadura de Pinochet, o governo precursor das práticas neoliberais: forte desregulação, desemprego maciço, repressão sindical, redistribuição de renda em favor dos ricos e privatização dos bens públicos (ANDERSON, 1995, p. 19). Mas foi a partir dos anos 1980 que os países latino-americanos em geral começaram a adotar o receituário neoliberal. Desde então, a estratégia de política econômica da América Latina passou voltar-se toda para um tema central: a renegociação da dívida externa.

Nesse mesmo período, em Washington, um grupo de economistas - do International Institute for Economy - pensavam o que deveria ser feito para que a América Latina conseguisse sair da crise (estagnação, inflação, dívida externa) em que estava inserida e retomar o crescimento. De uma reunião de 1989, voltada para discutir essa questão, elaborou-se consensualmente um conjunto de propostas de políticas e reformas requeridas para a "salvação" latino-americana. A esse conjunto John Williamson (1992, p. 12) chamou de "Consenso de Washington"2, cujo receituário de políticas foi utilizado pelos organismos internacionais - Fundo Monetário Internacional (FMI), Banco Mundial etc. - como condicionamento para a realização da tão requisitada renegociação da dívida externa dos países latino-americanos.

Para tanto, tiveram de seguir passo a passo a cartilha do Consenso, sempre levando em conta a idéia de que, para que a renegociação fosse possível, era indispensável gerar confiança nos órgãos

\footnotetext{
2 Williamson destaca dez propostas do receituário do "Consenso de Washington": (1) disciplina fiscal, ou seja, redução dos gastos públicos, na tentativa de manter um superávit orçamentário; (2) prioridades de gasto público - reduzir o papel do Estado na economia, redirecionando o gasto para as áreas desinteressantes para o investimento privado - geralmente, bens públicos; (3) reforma tributária, tornando a tributação menos progressiva; (4) liberalização financeira, cujo objetivo máximo é deixar que a taxa de juros seja determinada pelo mercado; (5) manutenção da estabilidade da taxa de câmbio; (6) liberalização comercial; (7) abolição das barreiras à entrada de investimentos externos diretos no país; (8) privatização das empresas estatais; (9) abolição das regras que impedem a entrada de novas firmas do setor e (10) o sistema legal deve assegurar direitos de propriedade (WILLIAMSON, 1993, p. 1332).
} 
financeiros internacionais, deixando de lado, portanto, a prática do chamado "populismo econômico" (BRESSER-PEREIRA, 1991) ${ }^{3}$.

Dessa maneira, os governos latino-americanos foram transferindo "capacidade de decisão" (FIORI, 2001, p. 33) para aquelas entidades internacionais, que passaram a ditar o que deveriam ou não fazer. Foi nesse contexto que a questão da governabilidade veio à tona, aparecendo como algo indispensável para o sucesso das reformas a serem realizadas. Ao mesmo tempo em que a governabilidade surgiu como necessária para as reformas, estas apareceram como o único caminho possível para evitar a ingovernabilidade; com isso, formou-se um círculo vicioso de que não se consegue escapar. $\mathrm{O}$ que deve ser questionado, levanta Fiori, resume-se a: "por que, por exemplo, uma alta taxa de inflação seria melhor indicador de ingovernabilidade do que uma alta taxa de desemprego? Por que o desequilíbrio fiscal mais do que o comercial? Ou ainda, por que uma baixa taxa de crescimento mais do que uma alta taxa de miséria e concentração de renda?" (FIORI, 1997, p. 39). Pode-se perceber, conclui ele, que o conceito de governabilidade é indeterminado e indeterminável do ponto de vista teórico. Não se trata de um conceito, "trata-se de uma categoria estratégica cujos objetivos imediatos podem variar segundo o tempo e o lugar mas que será sempre e irremediavelmente situacionista" (ibidem).

Embora tenha-se constituído como uma condicionalidade, o ideário neoliberal foi progressivamente ganhando espaço e obtendo, assim, legitimação. As evidências mostraram, entretanto, que o resultado da implantação de suas políticas consistiu no declínio constante das taxas de investimento e de crescimento. Ainda houve uma piora na distribuição de renda e um aumento do desemprego. Em suma, esse tipo de política passou a significar crise, exclusão social e falta de

\footnotetext{
3 Esse conceito tem sido abundantemente utilizado por economistas neoliberais como uma forma pejorativa de atacar o desenvolvimentismo. O "populismo econômico" vem sendo associado ao período desenvolvimentista e, ao ser olhado em um período em que o tema em voga é o do "ajuste" - os anos 1990 -, Bresser-Pereira (1991, p. 111) caracteriza-o da seguinte forma: "um tipo de afrouxamento fiscal que se define pela prática política de dizer sim às demandas de todos os setores da sociedade à custa do setor público".
}

investimentos no setor produtivo.

\section{AS RECOMENDAÇÕES DO BANCO MUNDIAL}

Como foi indicado, desde os anos 1980 o Banco Mundial vem atuando como importante formulador de recomendações políticas para os países da periferia e como disseminador, junto com o FMI, das políticas de cunho neoliberal.

A seguir sugiro que seus relatórios preconizam e pressupõem um certo tipo de ordem social. $\mathrm{Na}$ realidade, é um modelo de sociedade próprio da atual configuração social hegemônica, ou seja, referido a um mundo posterior à crise do Welfare State e, ainda, posterior à derrocada do mundo comunista.

Para isso, procurarei apresentar a teoria social implícita nos relatórios do Banco Mundial, que pressupõe, por um lado, um determinado tipo de Estado e, por outro, presume um mundo do trabalho específico.

Em relação ao Estado (BANCO MUNDIAL, 1997), de modo geral, os relatórios propõem que ele deve mudar - leia-se: realizar reformas - para que se adaptem ao mundo que se transforma; devem, desse modo, procurar aumentar sua eficiência. Isso significaria, segundo o Banco Mundial, que, no contexto atual, o Estado não deve ser mais o promotor direto do desenvolvimento, mas sim deixar essa tarefa para os mercados.

O Estado deve, portanto, retrair a sua atuação, de modo a tornar-se um catalisador, facilitador e parceiro dos mercados. Dessa forma, "os Estados devem complementar os mercados e não substituí-los" (idem, p. 18), devem voltar sua ação para a implantação e adaptação de instituições que estimulem um melhor desempenho dos mercados.

Assim, o Estado deve, por um lado, facilitar e garantir o bom funcionamento dos mercados; seu papel seria delineado pela necessidade de construírem-se novas instituições, modificar as existentes e eliminar as que não servem mais para tal objetivo. A provisão dessas instituições é referida pelo Banco como "boa governança" e inclui: criar um regime regulatório que atue juntamente com os mercados para promover a competição; criar um ambiente macro-econômico estável para a ação dos mercados, ou seja, criação de enabling environment, que gere certezas à iniciativa privada; eliminar a corrupção, que poderia subverter 
os objetivos das políticas, deslegitimando as instituições públicas que dão apoio aos mercados e, ainda, assegurar os direitos de propriedade (WORLD BANK, 2002, p. 99).

Por outro lado, o Estado deve complementar os mercados naqueles setores da produção de bens e serviços em que ao setor privado não interessa entrar. Por exemplo: na produção de bens públicos; em mercados que apresentam falhas ou, ainda, em prestação de serviços sociais àqueles que não conseguem pagar por eles.

Já no que diz respeito ao mundo do trabalho, é possível perceber nos relatórios do Banco Mundial que ele passa a estar dividido em dois. De um lado, estão os indivíduos que conseguem atuar no mercado - que seria o mecanismo de funcionamento "mais eficiente" da sociedade - e, de outro, estariam aqueles incapazes de integrar-se aos mercados - os pobres -, dos quais o Estado deve cuidar, por meio de suas políticas sociais residuais e focalizadas.

Nesse sentido, se o Estado proposto pelo Banco Mundial ainda reserva algum papel no âmbito econômico - complementar a e garantidor do bom funcionamento dos mercados -, no que tange à questão social, ou seja, à sua atuação no mundo do trabalho, pode-se perceber que o termo "Estado mínimo" é bastante adequado, uma vez que se percebe a tendência a uma drástica retração do seu papel de provedor de políticas sociais.

Esse novo mundo do trabalho pode ser recortado a partir das recomendações do Banco Mundial que se voltam para o "combate à pobreza", que têm sido elaboradas desde o início dos anos 1990. Esse tema foi tratado sobretudo nos Relatórios sobre o desenvolvimento mundial de 1990 e de 2000-2001, em que o Banco Mundial encarrega-se de instruir e recomendar aos países em desenvolvimento estratégias para o enfrentamento dos elevados custos sociais decorrentes das políticas de ajuste. Dessa maneira, nota-se que, em vez de tratar das conseqüências negativas do ajuste - como o alto nível de informalidade do trabalho e o aumento do desemprego - e propor soluções estruturais, as estratégias de combate dos custos sociais das políticas neoliberais são reduzidas à estratégia de "combater a pobreza".

Ao mesmo tempo em que o termo "pobreza" afirma-se como o alvo a ser combatido pelas polí- ticas sociais focalizadas e compensatórias, ele gera dúvidas em relação ao modo de ser definido. Segundo o Banco Mundial, a definição de pobreza consiste na "incapacidade de atingir um padrão de vida mínimo" (BANCO MUNDIAL, 1990, p. 27), de que podem ser destacadas duas questões diferentes: (i) o que é um padrão de vida mínimo? (ii) Que se entende por "incapacidade"?

A primeira questão apresenta-se mais como de caráter metodológico, a que o Banco Mundial apresenta a seguinte resposta: o padrão de vida mínimo deve ser avaliado pelo consumo, isto é, a despesa necessária para que se adquira um padrão mínimo de nutrição e outras necessidades básicas e, ainda, uma quantia que permita a participação da pessoa na vida cotidiana da sociedade. Assim, trata-se de calcular um valor mínimo para cada país (ou região) e, em seguida, comparar esse valor encontrado com a renda dos indivíduos. Aqueles que tiverem uma renda inferior a esse valor poderão ser considerados pobres e, portanto, sem condições de viver minimamente bem.

Já a segunda questão envolve temas mais amplos e diz respeito às estratégias de combate à pobreza. O termo "incapacidade" no discurso do Banco Mundial remete a duas questões: (a) oportunidades econômicas e (b) prestação de serviços sociais. Conseqüentemente, para combater a situação de pobreza de um indivíduo, devem ser implementadas políticas nesses dois campos.

A primeira das estratégias de redução da pobreza (a) tenta identificar políticas que estimulem a criação de novas oportunidades econômicas para que os pobres possam obter rendimentos. Assim, com mais renda, o indivíduo poderia ultrapassar a "fronteira" da pobreza e, dessa forma, ser considerado um não-pobre. Embora o Banco Mundial ressalte a importância do crescimento econômico na redução da pobreza - enquanto criador de oportunidades para os pobres -, quando se refere ao papel do Estado na política social, ele propõe políticas focalizadas de aumento do capital humano; a isso se refere o tópico (b).

Assim, a segunda estratégia de combate à pobreza proposta pelo relatório do Banco Mundial refere-se à necessidade de o governo prestar serviços sociais - educação e saúde - aos pobres. O documento ressalta a íntima relação da prestação de serviços sociais com a diminuição da pobreza, 
pois ela significa uma promoção de políticas focalizadas de aumento do "capital humano"4 dos indivíduos.

De acordo com esse documento, o investimento em capital humano é um dos meios mais importantes para reduzir a pobreza, pois "o principal bem dos pobres é o tempo para trabalhar. A educação aumenta a produtividade deste bem. O resultado, no nível individual, é uma renda mais alta, como demonstram muitos estudos" (idem, p. 85). A idéia presente seria, portanto, que, ao educar-se mais, o indivíduo torna-se mais apto a competir com os outros por um emprego melhor no mercado e, conseqüentemente, a obter uma renda maior. Assim, haveria uma contínua necessidade de ele buscar ser mais competitivo que os outros, por meio do aumento de sua "empregabilidade" 5 .

No relatório de 1990, portanto, percebe-se que o indivíduo integrado ao mercado define-se pelo fato de possuir "capital humano" (educação e saúde). Aqueles que não são munidos desse tipo de capital são incapazes de atuar no mercado, ou seja, não conseguem ser autônomos para competir com os outros. Esses indivíduos configurariam a definição de "pobres", com os quais o Estado deve preocupar-se, compensando-os com suas políticas

\footnotetext{
4 A teoria do capital humano afirma que as diferenças de rendas entre os indivíduos são influenciadas pelo capital humano (sobretudo educação) que cada um investe em si mesmo. Nas palavras de Theodore Schultz (1973, p. 31): "apesar do fato de que os homens adquirem habilidade e conhecimento úteis seja algo evidente, não é evidente entretanto que habilidade e conhecimentos sejam uma forma de capital, que esse capital seja em grande parte um produto do investimento deliberado, que nas sociedades ocidentais cresceu num ritmo muito mais rápido que o capital convencional (não humano), e que seu crescimento pode ser o traço mais característico do sistema econômico. Se observou amplamente que os incrementos da produção nacional têm sido relacionados em grande medida com os incrementos da terra, horas de trabalho e capital físico reproduzível. Mas o investimento em capital humano é provavelmente a principal explicação dessa diferença”. Em suma, o raciocínio básico pode ser assim sintetizado: (i) aumento da educação dos trabalhadores, (ii) estes terão suas habilidades e conhecimentos melhorados, (iii) quanto maiores as habilidades e conhecimentos, maior a produtividade do trabalhador; (iv) essa maior produtividade acaba gerando maior competitividade e, assim, maiores rendas para o indivíduo.

5 Conceito cunhado e difundido pelos organismos internacionais para expressar as novas exigências feitas aos trabalhadores frente à nova lógica da concorrência.
}

sociais focalizadas de aumento de capital humano.

No relatório de 2000-2001 (WORLD BANK, 2000-2001) o tema da pobreza foi retomado e procurou-se analisar as experiências acumuladas nos anos 1990 e propor novas estratégias para combatê-la. A pobreza é vista nesse documento de um modo um pouco diferente. Enquanto o relatório de 1990 avaliava a pobreza pela variável "renda", priorizando o seu lado monetário, o relatório de 2000-2001 considerou-a um fenômeno multifacetado, decorrente de múltiplas privações produzidas por processos econômicos, políticos e sociais que se relacionam entre si. Assim, além da forma monetária de pobreza, ela é considerada como ausência de capacidades, acompanhada da vulnerabilidade do indivíduo e de sua exposição ao risco.

Nesse relatório estão presentes as idéias de Amartya Sen (p. ex. SEN, 2001), para quem a questão da pobreza deve ser encarada pela idéia de privação de capacidades básicas de realizar (ou seja, de cada um alcançar os seus objetivos de vida) e não como uma carência de determinadas necessidades, argumentando que: (1) a pobreza pode ser sensatamente identificada em termos de privação de capacidades; a abordagem concentrase em privações que são intrinsecamente importantes (em contraste com a renda baixa, que é importante apenas instrumentalmente); (2) existem outras influências sobre a privação de capacidades - e, portanto, sobre a pobreza real - além do baixo nível de renda (a renda não é o único instrumento de geração de capacidades) e (3) a relação entre baixa renda e baixa capacidade é variável entre comunidades e até mesmo entre famílias e indivíduos (o impacto da renda sobre as capacidades é contingente e condicional) (SEN, 2000, p. 110).

Dessa forma, sob influência dos trabalhos de Amartya Sen e da evidência do agravamento das condições sociais, no decorrer destes últimos 10 anos, o tema da pobreza começou a ser visto como algo multidimensional e passa a ser definido como "privação de capacidades", que faz que o potencial do indivíduo em auferir renda seja diminuído.

Assim, enquanto o relatório de 1990 propunha uma dupla estratégia para lidar-se com o problema da pobreza, a estratégia proposta pelo relatório de 2000-2001 tem como tema central a ex- 
pansão das capacidades humanas das pessoas pobres.

Assim, nota-se que, para que o problema da pobreza como privação de capacidades seja resolvido, recorre-se, no relatório de 2000-2001, à noção de Sen de "desenvolvimento como liberdade" (idem), que nada mais é que o entendimento do desenvolvimento como um processo de expansão das liberdades humanas. Assim, para que a pobreza seja reduzida, faz-se necessário que o Estado atue apenas no sentido de aumentar essas liberdades e deve fazê-lo por meio da expansão das capacidades humanas dos pobres. Nesse sentido, pode-se perceber que, embora o conceito de capacidade humana seja mais abrangente que o de capital humano, ele também não pressupõe a existência de um Estado que garanta os direitos sociais, mas simplesmente a necessidade de um Estado caridoso, que tem deveres a cumprir apenas para com os pobres. A presença do Estado só seria necessária, portanto, em um primeiro momento, no sentido de aumentar as capacidades dos pobres, para, em um segundo momento, quando esses indivíduos já estivessem capacitados, o Estado já se tornaria desnecessário, passando a deixar que eles, individualmente, procurassem seu desenvolvimento pessoal no mercado.

\section{A CENTRALIDADE DA CATEGORIA "PO- BREZA"}

Como foi visto anteriormente, as políticas de combate à pobreza têm sido apresentadas como um alerta para os efeitos sociais negativos da globalização neoliberal e, para os países "em desenvolvimento", uma solução para os custos sociais decorrentes do ajuste percebidos nesses países. De fato, desde a segunda metade dos anos noventa, começou a surgir um movimento de autocrítica dentro dos organismos internacionais - como é o caso de Joseph Stiglitz (2002), exvice-Presidente do Banco Mundial -, questionando a maneira como as recomendações do Consenso de Washington vinham sendo adotadas pelos países "em desenvolvimento", já que o seu fracasso tornava-se cada vez mais evidente.

O que proponho aqui é que essas políticas de combate à pobreza sejam vistas justamente como um elemento próprio de uma teoria tácita presente nos documentos do Banco Mundial; referemse a um momento em que os prejuízos sociais tornaram-se patentes. Elas formam um conjunto de políticas sociais voltadas exclusivamente para a compensação, cujo alvo - a pobreza - é conceitualmente construído e faz parte de um modelo de sociedade específico.

Esse modelo de sociedade tem um formato bastante simples e seu "mundo do trabalho" é composto por dois tipos de indivíduos: o competitivo e o incapaz. O competitivo é aquele capaz de atuar livremente no mercado, uma vez que tem competitividade (empregabilidade) para conseguir um emprego, assegurar que não vai perder o que tem ou, ainda, se acontecer de perdê-lo, conseguir um novo emprego. O indivíduo incapaz é aquele que não consegue nada disso. Ele não tem empregabilidade, nem é competitivo, uma vez que não pôde (ou não quis) investir em seu próprio "capital humano".

O "mundo do trabalho" sofre, assim, uma transformação. O que antes constituía uma classe social (composta por trabalhadores "empregados" e "desempregados") agora forma um conjunto de indivíduos atomizados: os "competitivos" e os "incapazes" (pobres).

A construção de "pobreza" como conceito sociológico parte justamente desse tipo de raciocínio. O pobre é o indivíduo incapaz, que não consegue - ou não garante - o seu emprego e nem mesmo a sua subsistência. Conseqüentemente, a pobreza acaba sendo vista como um fracasso individual daquele que não consegue ser competitivo.

Assim, de acordo com as propostas do Banco Mundial, é desse pobre que o Estado deve cuidar. Com os outros indivíduos - os competitivos -, ele não precisa se preocupar, pois são capazes de garantir seu próprio sustento. É aos pobres, então, que a política social deve (e passa a) estar voltada. As recomendações do Banco Mundial, como foi observado, são todas focalizadas nos pobres, vistos como pessoas incapazes que necessitam de ajuda para inserirem-se no mercado. Portanto, suas propostas de políticas de combate à pobreza resumem-se apenas à transformação do indivíduo incapaz em um indivíduo capaz e competitivo, por meio do aumento de "capital humano" (no relatório de 1990) ou de "capacidade humana" (no relatório de 2000-2001).

Se, por um lado, esse tipo de política reforça a idéia de atomização e competitividade entre os indivíduos, por outro legitima a existência e a implantação de um Estado mínimo no campo social 
- e contribui, portanto, para a tentativa de destruição da democracia social alcançada pelo Estado de Bem-estar Social.

Na realidade, nos países em que o Estado de Bem Estar Social de fato instaurou-se, não houve uma total destruição da cidadania social, uma vez que os direitos sociais dos cidadãos já haviam sido consolidados e enraizados, como resultado de um longo processo ${ }^{6}$. Contudo, embora o Welfare State não tenha sido totalmente destruído, em muitos desses países sofreu abalos consideráveis, conforme indicou uma notícia de $O$ Globo: "Devido ao aumento da expectativa de vida e do número de desempregados, quase todos os países da Europa decidiram fazer cortes nos seus programas sociais. Aqueles que nos anos [19]80 eram vistos como modelo de um apoio amplo do Estado a pobres e aposentados estão mudando as suas políticas para reduzir os seus déficits orçamentários" (EUROPA DIMINUI APOSENTADORIAS, 2002, p. 45).

Já em países onde o Welfare State não foi implantado totalmente - em vários países "em desenvolvimento" -, ou seja, em lugares onde a população nunca pôde desfrutar de fato de seus direitos sociais de cidadão, esse modelo de sociedade neoliberal pôde penetrar muito mais facilmente, conseguindo destruir o pouco que existia de Welfare State ou, ainda, acabar com os projetos de implantá-lo plenamente. Essa inexperiência colabora para que as recomendações do Banco Mundial de combate à pobreza sejam tão bem aceitas e vistas como "bem-intencionadas" pelos países-alvos.

Enquanto o Banco Mundial vangloria-se de suas políticas com "face humana", que ensinam a lutar contra a pobreza, o conceito de cidadania social esvazia-se. A cidadania social, em sua essência, sempre esteve relacionada à garantia de direitos e não com programas compensatórios. Ela pressupõe um pacto social realizado pela sociedade como um todo, a partir do que se define que o Estado deve garantir uma proteção social - por meio dos direitos sociais - a todos os cidadãos, independentemente de sua renda, simplesmente

\footnotetext{
6 Segundo T. H. Marshall (1967), a partir do estudo da história da Inglaterra, o desenvolvimento da cidadania resume-se a uma história linear da aquisição dos direitos. Primeiro, alcançaram-se os direitos civis, no século XVIII, em seguida, adquiriram-se os direitos políticos, no século XIX, e por fim, como resultado desse processo de aquisição de direitos, vieram os direitos sociais, no século XX.
}

pelo fato de serem cidadãos. A cidadania social requer, desse modo, que exista um mínimo de solidariedade, induzida pela necessidade de solução dos conflitos sociais, e um sentimento de responsabilidade da sociedade para com a vida de cada um de seus membros.

Já a política social da "neo-sociedade" do liberalismo assume um caráter assistencialista, focalizando e restringindo seus serviços apenas àqueles que conseguem enquadrar-se na categoria "pobre", que acaba sendo, no final das contas, oca e bastante variável. Nesse processo, a democracia só tem a perder... Ela deixa de lado sua forma substantiva, reduzindo-se a uma democracia meramente formal.

\section{CONSIDERAÇÕES FINAIS}

O tema da "pobreza", ou ainda, da marginalidade, tem uma longa trajetória de pesquisa nas Ciências Sociais da América Latina, desde pelo menos os anos 1950. Assim, não se pode afirmar que a pobreza e a marginalidade sejam simples conseqüências do neoliberalismo; elas fazem parte da própria natureza do tipo de capitalismo desenvolvido nessa região.

Com essa ressalva, este artigo procurou demonstrar que a novidade introduzida nos anos 1990 foi que a categoria "pobreza" passou a ser uma peça-chave de uma ordem social implícita nos relatórios do Banco Mundial e hegemônica na formulação de políticas nos nossos países. Nesse sentido, as políticas de "combate à pobreza" estariam vinculadas a essa visão de mundo.

Sugeriu-se aqui que essa ordem social fundamenta-se a partir da visão neoliberal que vê o mercado como o principal organizador da sociedade e percebe essa sociedade composta por indivíduos atomizados. Dentro dessa lógica de atomização da sociedade, os indivíduos passam a ter de sobreviver por sua própria conta no mercado, em que são obrigados a competir uns com os outros e a conseguir maneiras de tornarem-se mais competitivos.

Como foi visto, os incapazes que não conseguem acompanhar esse processo passam a fazer parte do grupo dos pobres, para o qual o Estado deve voltar sua atenção, fazendo-lhes caridades das mais variadas, para que sejam dadas as condições mínimas de subsistência.

Para além de enfatizar que as políticas de "com- 
bate à pobreza" façam parte da própria lógica do marco teórico do neoliberalismo, assumindo um caráter focalizado e compensatório, este artigo pretendeu apontar para a possibilidade de que a excessiva utilização do conceito "pobreza" esteja enfraquecendo, ou mesmo substituindo, o de "cidadania social". Este conceito está comprometido com a idéia universalizada de direitos, a qual parece estar ausente na ordem social do neoliberalismo.

Vivian Domínguez Ugá (vividuga@globo.com) é Doutoranda em Ciência Política no Instituto Universitário de Pesquisas do Rio de Janeiro (IUPERJ).

\section{REFERÊNCIAS BIBLIOGRÁFICAS}

ANDERSON, P. 1995. Balanço do neoliberalismo. In : SADER, E. \& GENTILI, P. (orgs.). Pós-neoliberalismo : as políticas sociais e o Estado democrático. Rio de Janeiro : Paz e Terra.

BANCO MUNDIAL. 1990. Relatório sobre o desenvolvimento mundial. A pobreza. Washington, D. C. : Banco Mundial.

1997. O Estado em um mundo em transformação. Relatório sobre o desenvolvimento mundial. Washington, D. C. : Banco Mundial.

CASTRO, A. B. \& SOUZA, F. E. P. 1985. A economia brasileira em marcha forçada. Rio de Janeiro : Paz e Terra.

FIORI, J. L. 1997. Os moedeiros falsos. Petrópolis : Vozes. .2001. Brasil no espaço. Petrópolis : Vozes.

HOBSBAWM, E. J. 1995. Era dos extremos. O breve século XX - 1914-1991. Rio de Janeiro : Cia. das Letras.

MARSHALL, T. H. 1967. Cidadania, classe social e status. Rio de Janeiro : Zahar.

BRESSER-PEREIRA, L. C. (org.). 1991. Populismo econômico. Ortodoxia, desenvolvimentismo e populismo na América Latina. São Paulo : Nobel.
SCHULTZ, T. 1973. O capital humano : investimentos em educação e pesquisa. Rio de Janeiro : Zahar.

SEN, A. 2000. Desenvolvimento como liberdade. São Paulo : Cia. das Letras.

2001. Desigualdade reexaminada. Rio de Janeiro : Record.

STIGLITZ, J. 2002. Globalization and its Discontents. New York: W. W. Norton.

WALLERSTEIN, I. 2000. A reestruturação capitalista e o sistema-mundo. In : GENTILI, P. (org.). Globalização excludente. Petrópolis : Vozes.

WILLIAMSON, J. 1992. In Search of a Manual for Technopols. Washington : Institute For International Economics.

1993. Democracy and the "Washington Consensus". World Development, Washington, D. C., v. 21, n. 8, p. 1329-1336.

WORLD BANK. 2000-2001. World Development Report. Attacking Poverty. Washington, D. C. : The World Bank Group.

. 2002. World Development Report. Building Institutions for Markets. Washington, D. C. : The World Bank Group.

\section{OUTRAS FONTES}

Europa diminui aposentadorias e benefícios. 2002.

O Globo, Rio de Janeiro, 24.nov., p. 45. 